\title{
A respiratory rate of $\geqslant 60$ breaths per minute had high sensitivity for detecting hypoxia in infants
}

Rajesh VT, Singhi S, Kataria S. Tachypnoea is a good predictor of hypoxia in acutely ill infants under 2 months. Arch Dis

Child 2000 Jan;82:46-9.

QUESTION: In ill infants $<2$ months of age, can the respiratory rate be used as an indicator of hypoxia?

\section{Design}

Blinded comparison of respiratory rate with oxygen saturation level.

\section{Setting}

A hospital paediatric emergency service in Chandigarh, India.

\section{Participants}

200 infants who were $<2$ months of age (mean age 28 d) and had symptoms of any acute illness. Exclusion criteria were age $<24$ hours, major congenital malformations, previous admission to hospital, or active cardiopulmonary resuscitation.

Description of test and diagnostic standard The respiratory rate was counted for 1 minute while observing the infant's chest and abdominal movements when the infant was quiet. If the respiratory rate was $\geq 50$ breaths/minute, the rate was counted again after 30 minutes. The diagnostic standard was the assessment of oxygen saturation, which was measured at the finger or toe with a pulse oximeter (BCI, Waukesha, WI, USA). Hypoxia was defined as an oxygen saturation level $\leqslant 90 \%$.

\section{Main outcome measures}

Sensitivity and specificity for detecting hypoxia.

\section{Main results}

77 infants (39\%) had hypoxia. The table shows sensitivities, specificities, and likelihood ratios. The cutoff point of $\geq 60$ breaths/minute provided the best balance of sensitivity $(81 \%)$ and specificity $(68 \%)$.

\section{Conclusion}

In infants who were $<2$ months of age and had an acute illness, a respiratory rate of $\geq 60$ breaths/minute had a sensitivity of $81 \%$ and a specificity of $68 \%$ for detecting hypoxia.
Source of funding: not stated.

For correspondence: Dr S Singhi, Department of Pediatrics,

Postgraduate Institute of Medical Education and Research,

Chandigarh 160012

India. Fax +91172 744401.

Test characteristics for detecting hypoxia in infants with acute illnesses*

\begin{tabular}{lllll} 
Respiratory rate & Sensitivity $(95 \%$ Cl) & Specificity $(\mathrm{Cl})$ & +LR & -LR \\
\hline$\geqslant 40$ breaths/minute & $96 \%(89$ to 99$)$ & $37 \%(28$ to 46$)$ & 1.5 & 0.1 \\
\hline$\geqslant 50$ breaths/minute & $91 \%(82$ to 96$)$ & $59 \%(50$ to 68$)$ & 2.2 & 0.2 \\
\hline$\geqslant 60$ breaths/minute & $81 \%(70$ to 89$)$ & $68 \%(59$ to 76$)$ & 2.5 & 0.3 \\
\hline$\geqslant 70$ breaths $/$ minute & $51 \%(39$ to 62$)$ & $85 \%(77$ to 90$)$ & 3.3 & 0.6 \\
\hline$\geqslant 80$ breaths/minute & $22 \%(13$ to 33$)$ & $93 \%(88$ to 97$)$ & 3.4 & 0.8
\end{tabular}

Abbreviations defined in glossary; Cls and LRs calculated from data in article.

\section{COMMENTARY—continued from previous page}

Therefore, many of the "false positives" who were tachypneic but not hypoxic probably had serious illness. Indeed, tachypnea identified $72 \%$ of infants who died, whereas hypoxia identified only $53 \%$.

Both studies used the proper method for determining respiratory rate, as emphasised by others. ${ }^{2}$ The child should be observed in a quiet state, ideally when not febrile, and the respirations counted for a full 60 seconds by observing chest movement. In young children, the presence of fever and cough (without pneumonia) increases respiratory rate by approximately 10 breaths/minute. ${ }^{2}$ A similar difference is found between wakeful (but quiet) and sleeping children. ${ }^{3}$ Respiratory rates obtained by auscultation are on average $2-3$ breaths/minute higher than those obtained by observation, with greater differences (occasionally $\geqslant 10$ ) seen in wakeful children. ${ }^{3}$

These studies support the use of tachypnea as a diagnostic test to identify pneumonia and hypoxia in areas where radiography and pulse oximetry are not widely available. In areas with better access to these technologies, confirmatory tests should be used to guide treatment to avoid unnecessary treatment. This is especially true when patient populations have lower rates of serious illness, as is often the case in developed countries. Regardless of practice setting, all clinicians will improve their care of sick children by remembering to carefully assess respiratory status.

Michael B Aldous, MD, MPH University of Arizona College of Medicine Tucson, Arizona, USA

1 Margolis P, Gadomski A. Does this infant have pneumonia? JAMA 1998;279:308-13.

2 Dai Y, Foy HM, Zhu Z, et al. Respiratory rate and signs in roentgenographically confirmed pneumonia among children in China. Pediatr Infect Dis J 1995;14:48-50. 3 Rusconi F, Castagneto M, Gagliardi L, et al. Reference values for respiratory rate in the first 3 years of life. Pediatrics 1994;94:350-5. 